\title{
Volatile profiling in Rhus coriaria fruit (Sumac) from 3 different geographical origins and upon roasting as analyzed via solid-phase microextraction
}

\author{
Mohamed A Farag ${ }^{\text {Corresp., }}{ }^{1,2}$, Nesrin M Fayek ${ }^{1}$, Ibrahim Abou Reidah \\ 1 Pharmacognosy Department, College of Pharmacy, Cairo University, Cairo, Egypt \\ 2 Department of Chemistry, American University in Cairo, New Cairo, Egypt \\ 3 Department of Chemistry, An-Najah National University, Nablus, Palestine \\ Corresponding Author: Mohamed A Farag \\ Email address: mohamed.alifarag@aucegypt.edu
}

Rhus coriaria (Sumac) is a fruit grown worldwide for its fruit culinary use as flavoring agent and health benefits. Despite several studies on $R$. coriaria non-volatile metabolites, much less is recognized concerning volatiles composition within that genus. In an effort to expand on Sumac flavor profile and in its food products, we report on volatile profiling from 3 accessions of different origins including Palestine, Jordan and Egypt in addition to its cold beverage and post roasting via headspace solid-phase microextraction (SPME). Under optimized conditions, 74 volatile components were identified belonging to alcohols, aromatics, esters, ethers, furan/aldehyde, hydrocarbons, ketones, monoterpenes, oxides and sesquiterpene hydrocarbons. Major identified components included $\alpha$-pinene, naphthalene and o-cymene in Palestinian, Jordanian and Egyptian Sumac, respectively. Whereas, sesquiterpenes amounted for the major volatile class in fresh $R$. coriaria at ca. 40-58 \%, furan/aldehydes were the predominant classes in roasted fruits (58\%). Volatiles abundance data was further subjected to multivariate data analyses revealing furfural and nonanal enrichment in roasted compared to fresh fruits and its cold beverage preparation. Seeds exhibited no aroma components which justify for its removal in $R$. coriaria prior to its use as food flavor. Such knowledge is expected to be the key for understanding the olfactory and taste properties of $R$. coriaria and its several food products. 
1 Volatile profiling in Rhus coriaria fruit (Sumac) from 3 different geographical origins and 2 upon roasting as analyzed via solid-phase microextraction

3

4 Mohamed A. Farag ${ }^{1,2^{*}}$, Nesrin M. Fayek ${ }^{1}$, Ibrahim Abou Reidah ${ }^{3}$

5 7 11562, Cairo, Egypt

$8{ }^{2}$ Department of Chemistry, School of Sciences \& Engineering, The American University in 9 Cairo, New Cairo 11835, Egypt.

${ }^{3}$ Department of Chemistry, An-Najah National University, PO Box 7, Nablus 415, Palestine

\section{${ }^{*}$ Corresponding author: Mohamed A. Farag, email: Mohamed.farag@pharma.cu.edu.eg}

\section{Abstract}

Rhus coriaria (Sumac) is a fruit grown worldwide for its fruit culinary use as a flavoring agent aside from its health benefits. Despite several reports on $R$. coriaria non-volatile metabolites, much less is known concerning volatiles composition within that genus. In an effort to expand on sumac aroma profile, we report on volatiles profiling from 3 sites of different origins including Palestine, Jordan and Egypt in addition to its cold tea and post roasting via headspace solid-phase microextraction (SPME). Under optimized conditions, 74 volatile components were identified belonging to alcohols, aromatics, esters, ethers, furan/aldehyde, hydrocarbons, ketones, monoterpenes, oxides and sesquiterpene hydrocarbons. Major components in different sites included $\alpha$-pinene, naphthalene and o-cymene in Palestinian, Jordanian and Egyptian Sumac, respectively. Sesquiterpenes amounted for the major volatile class in fresh $R$. coriaria at $c a$. 40$58 \%$, whereas furan/aldehydes were the predominant classes in roasted fruits $(58 \%)$. The multivariate data analyses revealed that furfural and nonanal were more enriched in roasted fruits compared to both fresh fruits and fruits' cold tea preparation. Seeds exhibited no volatile components which justify for its removal prior to sumac fruit use. The change in volatile composition upon roasting is the key for understanding the olfactory and taste properties of $R$. coriaria and its several food products.

\section{Introduction}


Rhus coriaria L., (Family Anacardiaceae) is commonly known as sumac (Peter 2012). Sumac name is derived from 'sumaga', simply means red in Syrian language (Shabbir 2012). Sumac has been traditionally used in many Middle Eastern and Mediterranean countries as a spice, dying agent, and medicinal herb (Reidel et al. 2017). It is widely used as a condiment in Turkey and Iran to enhance the taste of poultry and vegetable dishes (Ravindran et al. 2012). In Arab countries, sumac is mixed with sesame seeds, salt and thyme in the popular spice mixture called za'atar (or dukkah). With regards to its cosmetic use, oils, phytopigments, and proteins derived from the sumac fruit were used in hair care products as anti-dandruff agents, hair colors, and hair cleaning agents, respectively (Gupta et al. 2010). Additionally, antioxidants from the sumac fruits were applied to stabilize sunflower oil (Rayne \& Mazza 2007). In terms of its folk medicinal use, sumac is reported for treating diarrhea and dermatological problems in addition to reduction of blood glucose, uric acid and cholesterol levels (Candan 2003; Mamedov et al. 2005; Mozaffarian 2013). With regards to its health benefits, $R$. coriaria also exerts a myriad of biological effects such as antimicrobial, antiviral, antioxidant, anti-inflammatory, anticancer, hepatoprotective, antihypertensive and cardiovascular protection (Bozan et al. 2003; El Hasasna et al. 2015; Pourahmad et al. 2010; Rayne \& Mazza 2007). Bioactive agents reported in $R$. coriaria (Abu-Reidah et al. 2014) include organic acids, fatty acids, essential and non-essential amino acids, vitamins $\left(\mathrm{B}_{1}, \mathrm{~B}_{2}, \mathrm{~B}_{6}, \mathrm{~B}_{12}, \mathrm{C}, \mathrm{PP}\right)$, carbohydrates (xylose and glucose), minerals (K, $\mathrm{Ca}, \mathrm{Mg}, \mathrm{Na}, \mathrm{P}, \mathrm{Fe}$ ), tannins, phenolic acids, anthocyanins, flavonoids and terpenoids (AbuReidah et al. 2015; Demchik et al. 2015; Kossah et al. 2010; Kossah et al. 2009). Although $R$. coriaria is not recognized as an aromatic plant, its fruit is enriched in essential oil composed of monoterpenes and/or sesquiterpenes (Bahar \& Altug 2009; Giovanelli et al. 2017; Morshedloo et al. 2017). Main aroma compounds include nonanal, limonene, 2-decenal, p-anisaldehyde (Giovanelli et al. 2017; Kurucu et al. 1993), (E)-caryophyllene (Bahar \& Altug 2009; Brunke et al. 1993; Gharaei et al. 2013) and the diterpene cembrene (Gharaei et al. 2013; Giovanelli et al. 2017). Volatile composition in plants is known to be affected by various factors such as geographical origin, harvesting time, processing and agricultural practices (Morshedloo et al. 2015). Previous studies have revealed for differences in Sumac volatile composition as affected by its origin i.e. Turkey, Italy and Iran. Nevertheless, no report has been made on assessing to what extent roasting could affect its aroma profile. 
61 The main objectives of this study were: 1) to assess volatile composition of sumac fruit from 62 different Middle-Eastern origins viz. Egypt, Jordan and Palestine using headspace SPME, 2) to assess roasting impact on its aroma profile and 3) to determine sumac cold tea true aroma profile. Volatiles abundance data were extracted from chromatograms without prior peak identification in an untargeted manner. Considering the complexity of acquired data, unsupervised and supervised multivariate data analyses viz. principal component analysis (PCA) and orthogonal partial least squares (OPLS), respectively, were employed for classification of fruit samples, and to ensure good analytical rigorousness. To the best of our knowledge, this study provides the first volatiles characterization in $R$. coriaria from the Middle East region and to report roasting impact on the fruit aroma.

\section{Materials and methods}

\subsection{Plant material}

Rhus coriaria fruits were collected manually in the full ripe stage from wild trees grown in Nablus, Palestine in October 2016, and were authenticated by Prof. Dr. Ibrahim Abou Reidah, Department of Chemistry, An-Najah National University, Nablus, Palestine. Commercial samples of $R$. coriaria fruits in the full ripe stage were purchased from El Hen herbal company, Amman, Jordan and Haraz Drug store, Cairo, Egypt. Voucher specimens were kept at the Department of Pharmacognosy, Faculty of Pharmacy, Cairo University, Egypt. Cold tea of the Palestinian sample was prepared by percolating $10 \mathrm{~g}$ of fresh cut fruits (without seeds) in $100 \mathrm{~mL}$ distilled water for $10 \mathrm{~min}$, kept at $25^{\circ} \mathrm{C}$, then filtered on Whatman filter paper to remove plant debris. Roasting of the Palestinian sample was carried out by heating fresh cut fruits (without seeds) in an oven set at $120^{\circ} \mathrm{C}$ for $20 \mathrm{~min}$. Three replicates were analyzed for each sample. The fruits were stored at $-20^{\circ} \mathrm{C}$ till further analysis.

\subsection{Chemicals and Materials}

SPME fibers of stableflex coated with divinylbenzene/carboxen/polydimethylsiloxane (DVB/CAR/PDMS, 50/30 $\mu \mathrm{m})$ (57328-U) or PDMS (polydimethylsiloxane) (57302) were purchased by Supelco (Oakville, ON, Canada). All other chemicals and standards were purchased from Sigma Aldrich, USA.

\subsection{Volatiles analysis of fresh and roasted fruits}


90 The HS-SPME volatile analysis was carried out as stated previously (Farag et al. 2017). Fruits 91 (100 mg) were cut into halves, placed in SPME screw cap vials (1.5 ml) and spiked with $(Z)$-392 hexneyl acetate dissolved in water at a final concentration of $2 \mu \mathrm{g}$ per vial. The SPME fiber 93 was inserted manually into a vial containing seeds placed in an oven kept at $50^{\circ} \mathrm{C}$ for $30 \mathrm{~min}$. 94 The fiber was subsequently withdrawn into the needle and then injected into the injection port 95 of the gas chromatography-mass spectrometer (GC-MS). GC-Ms analysis was performed on a 96 Schimadzu GC-17A gas chromatogram (Schimadzu, Tokyo, Japan) equipped with DB-5 97 column $(30 \mathrm{~m} \times 0.25 \mathrm{~mm}$ i.d. $\times 0.25 \mu \mathrm{m}$ film thickness; Supelco $)$ and coupled to Schimadzu QP5050A mass spectrometer. The interface and the injector tempreatures were both set at $220^{\circ} \mathrm{C}$. The following gradient temperature program was used for volatiles analysis. The oven temperature was kept first at $40^{\circ} \mathrm{C}$ for $3 \mathrm{~min}$, then increased to $180^{\circ} \mathrm{C}$ at a rate of $12^{\circ} \mathrm{C} \mathrm{min}^{-1}$, kept at $180^{\circ} \mathrm{C}$ for $5 \mathrm{~min}$, and finally ramped at a rate of $40^{\circ} \mathrm{C} \min ^{-1}$ to $240^{\circ} \mathrm{C}$ and kept at this temperature for $5 \mathrm{~min}$. The carrier gas helium was used at a total flow rate of $0.9 \mathrm{~mL} / \mathrm{min}$. Splitless injection mode was used for analysis considering the lower levels of volatiles in samples. SPME fiber was prepared for the next analysis by placing it in the injection port for 2 min at $220^{\circ} \mathrm{C}$ to ensure complete elution of volatiles. Blank runs were made during sample analyses. The HP quadruple mass spectrometer was operated in EI mode at $70 \mathrm{eV}$. A scan range was set at $m / z 40-500$.

\subsection{GC-MS data processing and multivariate analysis}

Volatile components were identified by comparing their retention indices (RI) relative to nalkanes (C6-C20), mass matching to NIST, WILEY library database and with standards whenever available. Peaks were first deconvoluted using AMDIS software

112 (http://www.amdis.net) prior to mass spectral matching. Volatiles abundance data were prepared 113 for multivariate data analysis by extraction using MET-IDEA software (Broeckling et al. 2006) 114 for data extraction. Data were then subjected to principal component analysis (PCA), partial least 115 squares-discriminant analysis (OPLS-DA) using SIMCA-P version 13.0 software package

116 (Umetrics, Umea, Sweden). Markers were subsequently identified by analyzing the S-plot, which 117 was declared with covariance (p) and correlation (pcor). All variables were mean centered and 118 scaled to Pareto variance.

\section{Results}


120

121

122

123

124

125

126

127

128

129

130

131

132

133

134

135

136

137

138

139

140

141

142

143

144

145

146

147

148

149

\subsection{Volatiles analysis of fresh $\boldsymbol{R}$. coriaria fruit (Sumac) from three different geographical} origins

GC-MS analysis (Table $1 \& 2$, Figure 1) of sumac fruits led to the identification of 74 volatile constituents, categorized in 10 different classes viz. alcohols, aromatics, esters, ethers, furan/aldehydes, hydrocarbons, ketones, monoterpene hydrocarbons, oxide and sesquiterpene hydrocarbons. A typical chromatogram of fresh and roasted sumac fruit aroma profiles is represented in Figure 1. Initial detection of volatiles started from zero minutes during chromatographic run but considering that no volatile peaks were detected till 5 minutes and with only one major peak for acetic acid (Fig. S1), MS detection started from 5 minutes for all specimens. Considering our interest in volatile terpenoids and hydrocarbons, five minutes delay is appropriate for this study. Acetic acid in sumac is likely to derive the tartar taste for its fruit. Sesquiterpene hydrocarbons amounted for the most dominant class accounting for $c a$. 40-58\% of the fresh Sumac aroma with a total of 26 identified volatile constituents (Table 2). Next to sesquiterpenes, monoterpene hydrocarbons represented the most abundant class (ca. 17-34\%) among specimens (Table 2). Other 8 volatile classes detected amounted for less than 17\% of sumac fruit total volatile blend (Table 2). Naphthalene and $\alpha$-pinene were the major volatile forms in Jordan and Palestine specimens at $c a .15 .8$ and 16.7\%, respectively. Whereas, monoterpene hydrocarbons viz., o-cymene $7.7 \%$, $\beta$-ocimene $7.5 \%$ and limonene $7.3 \%$ were the chief components in fresh sumac fruit aroma derived from Egypt. Volatiles found at comparable levels in all 3 examined specimens included $(E)$ - $\beta$-famesene and $(Z, Z)$ - $\alpha$-farnesene (sesquiterpene hydrocarbons) detected at ca. 6-8\%. With regard to oxides, cineole amounted for $7.3 \%$ of Egyptian sumac aroma blend, at two fold levels that present in specimens from Jordan $(3.2 \%)$ and Palestine (2.2\%) (Table 1$)$.

In contrast, roasted fruit aroma was predominated by furan/aldehydes at $c a$. $58 \%$ followed by sesquiterpene hydrocarbons at 27\%. A dramatic change in fruits aroma profile was observed upon roasting exemplified in high furan/aldehyde (58.1\%) and ketone (6.1\%) levels in roasted fruit concurrent with a marked decrease in the other 8 volatile classes (Table 2). Roasted specimens were particularly enriched in furfural $(34.3 \%)$ and $(E)$-nonanal $(12.2 \%)$ followed by 3-thujanone (5.1\%) (Table 1, Fig. 2). Sumac fruits are also used worldwide to prepare cold tea by simply soaking the fruit in cold water. Consequently, it was of interest to characterize the 
150 sumac cold tea aroma profile; a weak aroma profile was detected compared to fruit exemplified

151 by much lower number of volatile components totaling 14 peaks (Fig. 2).

152 It should be noted that a relatively high standard deviation was observed for some minor 153 constituents (Table 1) viz., $\beta$-linalool, styrene, octanal, nonanal and $\beta$-ocimene especially from

154 Jordanian specimen. Whether such large variance is associated with the experimental setup and 155 detection method has yet to be determined, Employing other detectors viz. (Flame Ionization 156 Detector). FID detection or automated SPME in volatiles extraction step can help minimize such 157 variance.

3.2 Multivariate PCA and OPLS-DA analyses of fresh, roasted and cold tea of $\boldsymbol{R}$. coriaria fruit volatiles data

162

163

164

165

166

167

168

169

170

171

172

173

174

175

176

177

178

179

180

Multivariate PCA (Figures 3, 4 \& S2) was carried out to explore the relative variability within the different specimens and to identify geographical origin (viz. Egypt, Jordan and Palestine) impact on fresh sumac fruit aroma in an untargeted manner. Multivariate data analyses additionally help in identifying potential markers for each fruit origin. Palestinian and Jordanian sumac specimens were found more or less clustered together on the right side of PC1 (positive score values). In contrast, Egyptian sumac was positioned on the left side of PC1 (Fig. 3A). A total of 74 volatiles abundance data were subjected to PCA analysis with two major principle components (PC1/PC2) accounting for $60 \%$ of the total variance. PCA loading plot (Fig. 3B) revealed that $\alpha$-pinene contributed the most positively along PC1 and PC2, being most abundant in Palestinian Sumac in agreement with results presented in (Table 1). In contrast, $o$-cymene and limonene located on the far negative side of PC1 were more enriched in Egyptian specimens. Roasting was found to influence sumac aroma profile more than the growth habitat as revealed from PCA analysis (Figure 4A). Roasted specimens were positioned to the right side of PC1 (positive side) being most distant in composition, whereas fresh fruits and cold beverage specimens were all positioned together on the left side of PC1 (negative side). PCA model (Figure 4A) was prescribed by PC1 and PC2 accounting for $45 \%$ and $24 \%$ of the variance, respectively. Unique aroma compounds found in roasted specimens included furfural and nonanal (Figure 4B). To help identify volatile markers unique for roasted specimens, OPLS-DA (orthogonal projection to latent structures-discriminant analysis) was employed (Figure S2). 
181 OPLS-DA score plot of roasted versus unroasted fruit showed a clear segregation between 182 roasted and fresh samples explaining 97\% of the total variance (R2) and with a prediction

183

184

185

186

187

188

189

190

191

192

193

194

195

196

197

198

199

200

201

202

203

204

205

206

207

208

209

210

211

goodness parameter Q2=95\%. The respective S-plot (a remarkable parameter that compares the variable magnitude versus its reliability in OPLS) identified furfural and nonanal as markers of roasting process (Figure S2-B) and in agreement with PCA analysis. OPLS-DA model of cold sumac tea modelled against fresh fruit failed to provide a fit model as in roasted specimen case, with lower R2 and Q2 values of 85\% and 89\% respectively (Figure S2-C). In general, the aroma of sumac cold tea appeared to be more dominated by esters viz. bornyl acetate, nerol acetate and s esquiterpenes viz. ( $\square$ )-caryophyllene and $\square$-humulene, as revealed from derived S plot (Figure S2-D).

\section{Discussion}

Sumac is commonly used as spice or appetizer, simply by blending its dried grounded fruits with freshly cut onion, or being mixed with plant oil or added to poultry dishes (Kossah et al. 2009; Shabbir 2012) in addition to being incorporated in several nutraceutical products (Wang \& Zhu 2017). Also, sumac fruits oil and protein were used in hair care products (Gupta et al. 2010).

The main objective of this study was to explore the variation in volatile compositions among $R$. coriaria from 3 different sites including Palestine, Jordan and Egypt and to assess the impact of roasting on fuits' volatile constituents. With regards to the impact of growth habitat on sumac volatiles profile, fruit specimens derived from Jordan and Palestine appeared to be similar in volatiles composition and being distant from that of Egypt. Such result is expected considering the close geographical location of Jordan and Palestine and similar climatic conditions. Abundance of monoterpenes has been reported in sumac fruit grown in Italy (Giovanelli et al. 2017; Reidel et al. 2017), with $\alpha$-pinene, $\beta$-ocimene and fenchone as the main components. Whereas, prevalence of sesquiterpenes was reported in sumac fruit originated from Turkey and Iran (Bahar \& Altug 2009; Gharaei et al. 2013; Morshedloo et al. 2018) with $\beta$-caryophyllene as the most abundant. It should be noted that nonadecane (Bahar \& Altug 2009) and p-anisaldehyde (Giovanelli et al. 2017), previously reported as major components of $R$. coriaria essential oil, were not detected in the current study. Such discrepancy could be attributed to either the different collection methods that is SPME adopted herein involving no heat treatment in contrary to steam distillation or to regional differences owing to agricultural or ecological factors (Bahar \& Altug 2009; Giovanelli et al. 2017). 
212 Upon roasting, a marked variation in volatiles profile was detected. This variation is exemplified

213 in higher furfural and nonanal levels in roasted samples. Likewise, previous reports (Bahar \& 214 Altug 2009; Giovanelli et al. 2017; Morshedloo et al. 2018; Reidel et al. 2017) on fresh sumac

215 fruit analyzed using SPME from Turkey, Italy and Iran reported for furfural and nonanal 216 presence at trace levels, suggesting that these are key markers indicative of the roasting process.

217 Elevated levels of nonanal (23\%) were only detected in hydro-distilled Sumac fruit in which

218 heating was applied comparable to that of roasting effect (Morshedloo et al. 2018). Our results

219 suggest that both furural and nonanal can be utilized as markers to distinguish between roasted

220 and fresh Sumac samples or to predict whether degradation has occurred in sumac fruits upon

221 storage at elevated temperature. Sumac fruits are enriched in both reducing sugar (xylose) and

222 amino acids (Demchik et al. 2015), regarded as the precursor compounds for Millard reaction

223 likely to occur in sumac fruits upon roasting (Tamanna \& Mahmood 2015). Furfurals are major

224 products of Maillard reaction detected in roasted coffee and cocoa beans (Martins et al. 2000),

225 roselle (Farag et al. 2015) and during processing of soyabeans, pasta and meat (Tamanna \&

226 Mahmood 2015). Maillard reaction involves the reaction of amino acid with a reducing sugar in

227 the presence of heat, typical of the roasting process (Nie et al. 2013; Yaylayan 2006). Although,

228 furans are of common occurrence in thermal processed foods, increasing awareness of furans

229 health hazard as a possible carcinogen is recognized (Nie et al. 2013; Reinhard et al. 2004).

230 According to the FDA guidelines, average permitted level of furan should not exceed $170 \mathrm{ng} / \mathrm{g}$

231 (FDA 2004).

232 In order to identify geographical origin (viz. Egypt, Jordan and Palestine) impact on fresh sumac

233 fruit aroma profile in an untargeted manner and to help in identifying potential markers for each

234 fruit origin, PCA was attempted to model the volatiles abundance data. Palestinian and

235 Jordanian sumac specimens clustered together distant from that of Egyptian sumac. In an attempt

236 to evaluate the effect of heat on sumac, roasting was carried out as previously explained

237 (experimental section). The respective S-plot showed a marked increase in furfural and nonanal 238 upon roasting. Such high furan levels (up to 40\%) in roasted specimens warrants more for its 239 quantification in sumac heated food products for safety and health issues.

240 Conclusion 
241 In the present study, we provide the first comprehensive volatile profile of Sumac fruits from 3

242 different Mid-Eastern countries. A total of 74 different volatile constituents were identified with 243 sesquiterpene hydrocarbons as main class followed by monoterpene hydrocarbons. Egyptian

244 Sumac was more enriched in $o$-cymene, $\beta$-ocimene and limonene. Whereas, Jordanian and

245 Palestinian specimens exhibited more close volatile profile being enriched in naphthalene and $\alpha$ 246 pinene. A significant alteration in sumac aroma profile was observed upon roasting, 247 accompanied by a marked increase in furan/aldehydes viz. furfural, 5-methyl furfural, concurrent 248 with a decrease in sesquiterpene and monoterpene hydrocarbons. The prevalence of furans in 249 roasted sample suggest for a distinct change in fruit aroma upon heating and for moreover the 250 monitoring of its furan levels considering its health hazardless. Our volatiles profiling provided 251 the true aroma profile in Sumac fruit growing in the Middle-East, which can be further applied 252 for investigating other factors such as storage, ripening stage, and analyzing its various 253 commercial food products.

254

255

256

257

258

259

260

261

262

263

264

265

266

267

268

269

270

271

272

273

274

275

276

277

278

279

\section{REFERENCES}

Abu-Reidah IM, Ali-Shtayeh MS, Jamous RM, Arráez-Román D, and Segura-Carretero A. 2015. HPLC-DAD-ESI-MS/MS screening of bioactive components from Rhus coriaria L.(Sumac) fruits. Food chemistry 166:179-191.

Abu-Reidah IM, Jamous RM, and Ali-Shtayeh MS. 2014. Phytochemistry, pharmacological properties and industrial applications of Rhus coriaria L.(Sumac). Jordan Journal of Biological Sciences 7.

Bahar B, and Altug T. 2009. Flavour characterization of sumach (Rhus coriaria L.) by means of GC/MS and sensory flavour profile analysis techniques. International Journal of Food Properties 12:379-387.

Bozan B, Kosar M, Tunalier Z, Ozturk N, and Baser K. 2003. Antioxidant and free radical scavenging activities of Rhus coriaria and Cinnamomum cassia extracts. Acta Alimentaria 32:53-61.

Broeckling CD, Reddy IR, Duran AL, Zhao X, and Sumner LW. 2006. MET-IDEA: data extraction tool for mass spectrometry-based metabolomics. Analytical chemistry 78:4334-4341.

Brunke EJ, Hammerschmidt FJ, Schmaus G, and Akgül A. 1993. The essential oil of Rhus coriaria L. fruits. Flavour and fragrance journal 8:209-214.

Candan F. 2003. Effect of Rhus coriaria L.(Anacardiaceae) on superoxide radical scavenging and xanthine oxidase activity. Journal of enzyme inhibition and medicinal chemistry 18:5962.

Demchik S, Rajangam A, Hall J, and Singsaas E. 2015. Fatty Acids, Carbohydrates and total proteins of wild sumac (Rhus typhina L.) drupes from the upper Midwest of the United States. American Journal of Essential Oils and Natural Products 3:30-34.

El Hasasna H, Athamneh K, Al Samri H, Karuvantevida N, Al Dhaheri Y, Hisaindee S, Ramadan G, Al Tamimi N, AbuQamar S, and Eid A. 2015. Rhus coriaria induces 
senescence and autophagic cell death in breast cancer cells through a mechanism involving p38 and ERK1/2 activation. Scientific reports 5:13013.

Farag MA, Ali SE, Hodaya RH, El-Seedi HR, Sultani HN, Laub A, Eissa TF, Abou-Zaid FO, and Wessjohann LA. 2017. Phytochemical profiles and antimicrobial activities of Allium cepa red cv. and A. sativum subjected to different drying methods: a comparative MSbased metabolomics. Molecules 22:761.

Farag MA, Rasheed DM, and Kamal IM. 2015. Volatiles and primary metabolites profiling in two Hibiscus sabdariffa (roselle) cultivars via headspace SPME-GC-MS and chemometrics. Food Research International 78:327-335.

FDA U. 2004. Exploratory data on furan in food.

Gharaei A, Khajeh M, Ghaffari M, and Choopani A. 2013. Iranian Rhus coriaria (sumac) essential oils extraction. Journal of Essential Oil Bearing Plants 16:270-273.

Giovanelli S, Giusti G, Cioni PL, Minissale P, Ciccarelli D, and Pistelli L. 2017. Aroma profile and essential oil composition of Rhus coriaria fruits from four Sicilian sites of collection. Industrial Crops and Products 97:166-174.

Gupta A, Malviya R, Singh TP, and Sharma PK. 2010. Indian medicinal plants used in hair care cosmetics: a short review. Pharmacognosy Journal 2:361-364.

Kossah R, Nsabimana C, Zhang H, and Chen W. 2010. Optimization of extraction of polyphenols from Syrian sumac (Rhus coriaria L.) and Chinese sumac (Rhus typhina L.) fruits. Research Journal of Phytochemistry 4:146-153.

Kossah R, Nsabimana C, Zhao J, Chen H, Tian F, Zhang H, and Chen W. 2009. Comparative study on the chemical composition of Syrian sumac (Rhus coriaria L.) and Chinese sumac (Rhus typhina L.) fruits. Pakistan Journal of Nutrition 8:1570-1574.

Kurucu S, Koyuncu M, Güvenç A, Baser K, and Özek T. 1993. The essential oils of Rhus coriaria L.(Sumac). Journal of Essential Oil Research 5:481-486.

Mamedov N, Gardner Z, and Craker LE. 2005. Medicinal plants used in Russia and Central Asia for the treatment of selected skin conditions. Journal of herbs, spices \& medicinal plants 11:191-222.

Martins SI, Jongen WM, and Van Boekel MA. 2000. A review of Maillard reaction in food and implications to kinetic modelling. Trends in Food Science \& Technology 11:364-373.

Morshedloo MR, Craker LE, Salami A, Nazeri V, Sang H, and Maggi F. 2017. Effect of prolonged water stress on essential oil content, compositions and gene expression patterns of mono-and sesquiterpene synthesis in two oregano (Origanum vulgare L.) subspecies. Plant Physiology and Biochemistry 111:119-128.

Morshedloo MR, Ebadi A, Maggi F, Fattahi R, Yazdani D, and Jafari M. 2015. Chemical characterization of the essential oil compositions from Iranian populations of Hypericum perforatum L. Industrial Crops and Products 76:565-573.

Morshedloo MR, Maggi F, Neko HT, and Aghdam MS. 2018. Sumac (Rhus coriaria L.) fruit: Essential oil variability in Iranian populations. Industrial Crops and Products 111:1-7.

Mozaffarian V. 2013. Identification of medicinal and aromatic plants of Iran.

Nie S, Huang J, Hu J, Zhang Y, Wang S, Li C, Marcone M, and Xie M. 2013. Effect of pH, temperature and heating time on the formation of furan in sugar-glycine model systems. Food Science and Human Wellness 2:87-92.

Peter KV. 2012. Handbook of herbs and spices: Elsevier.

Pojero ML. 1891. Flora sicula: descrizione delle plante vascolari spontanee o indigenate in Sicilia. 
326

Pourahmad J, Eskandari MR, Shakibaei R, and Kamalinejad M. 2010. A search for hepatoprotective activity of aqueous extract of Rhus coriaria L. against oxidative stress cytotoxicity. Food and Chemical Toxicology 48:854-858.

Ravindran P, Pillai G, and Divakaran M. 2012. Other herbs and spices: mango ginger to wasabi. Handbook of Herbs and Spices (Second Edition), Volume 2: Elsevier, 557-582.

Rayne S, and Mazza G. 2007. Biological activities of extracts from sumac (Rhus spp.): a review. Plant foods for human nutrition 62:165-175.

Reidel B, Vanessa R, Cioni PL, Majo L, and Pistelli L. 2017. Evolution of volatile emission in Rhus coriaria organs during different stages of growth and evaluation of the essential oil composition. Chemistry \& biodiversity.

Reinhard H, Sager F, Zimmermann H, and Zoller O. 2004. Furan in foods on the Swiss marketmethod and results. Mitteilungen aus Lebensmitteluntersuchung und Hygiene 95:532535.

Shabbir A. 2012. Rhus coriaria linn, a plant of medicinal, nutritional and industrial importance: a review. J Anim Plant Sci 22:505-512.

Tamanna N, and Mahmood N. 2015. Food processing and maillard reaction products: effect on human health and nutrition. International journal of food science 2015.

Wang S, and Zhu F. 2017. Chemical composition and biological activity of staghorn sumac (Rhus typhina). Food chemistry 237:431-443.

Yaylayan V. 2006. Precursors, formation and determination of furan in food. Journal für Verbraucherschutz und Lebensmittelsicherheit 1:5-9. 
Figure 1

Representative SPME-GC-MS chromatogram of fresh R. coriaria fruit (Sumac) collected from Egypt, Jordan and Palestine.

Assigned peak numbers follow that listed in Table 1

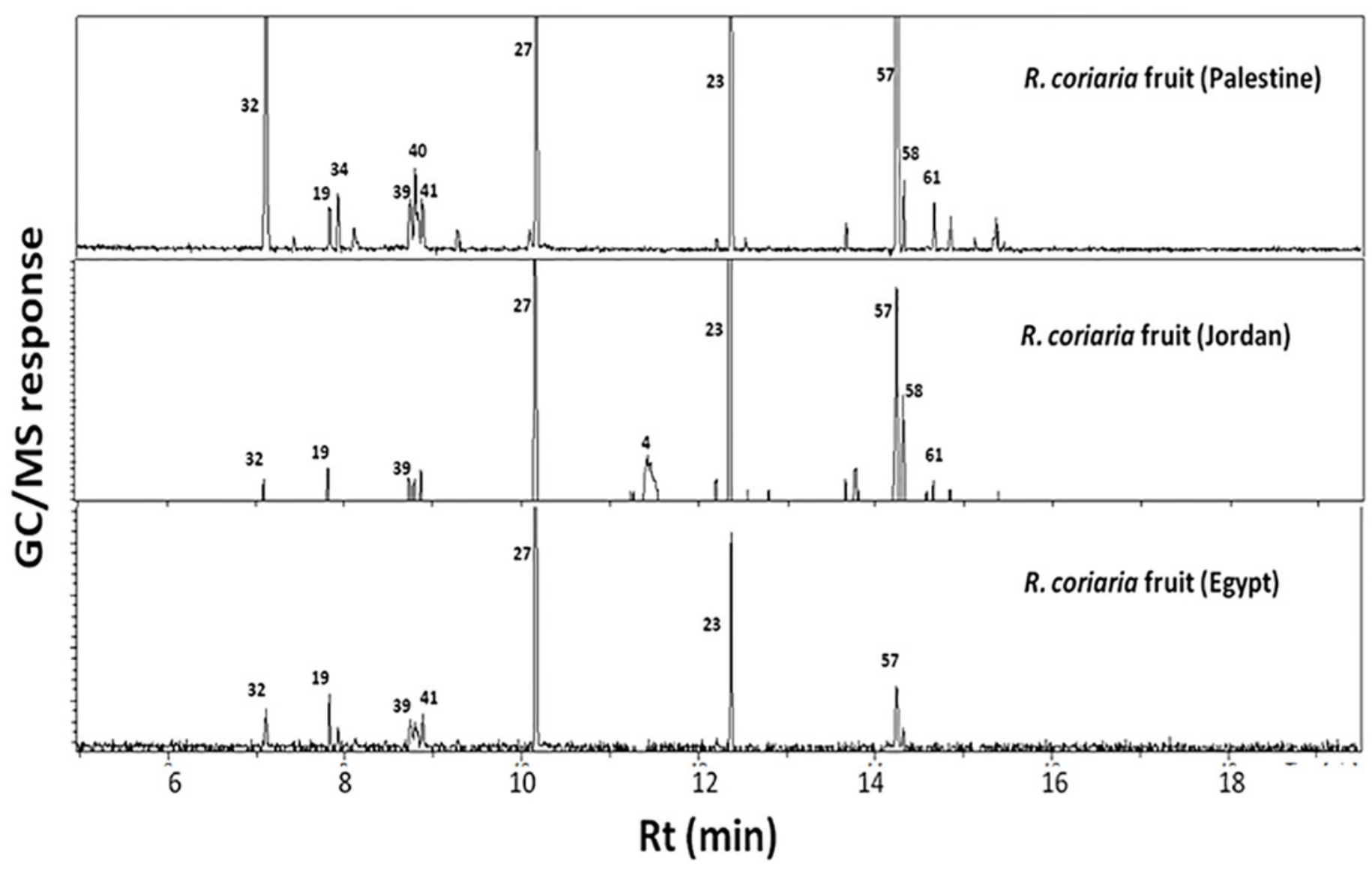


Figure 2

Representative SPME-GC-MS chromatogram of fresh, cold tea and roasted $R$. coriaria fruit (Sumac) from Palestine.

Assigned peak numbers correspond to volatiles listed in Table 1.

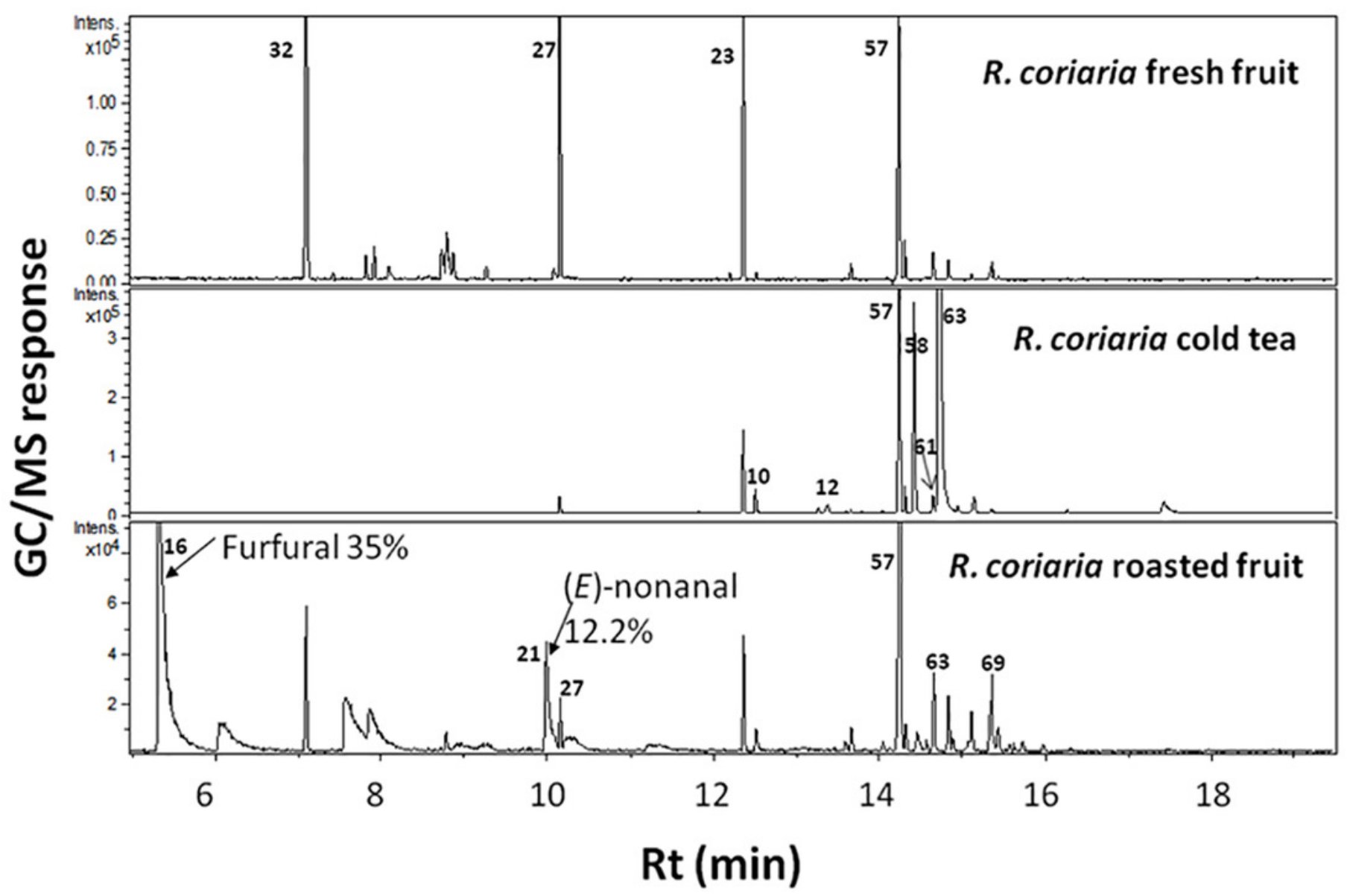


Figure 3

Principal component analyses of fresh $R$. coriaria fruit (Sumac) from 3 Middle East sites analyzed by SPME-GC-MS $(n=3)$.

Clusters are located at the distinct positions in two-dimensional space described by two vectors of principal component $1(\mathrm{PC} 1)=31 \%$ and $\mathrm{PC2}=29 \%$. (A) Score Plot of PC1 vs. PC2 scores. (B) Loading plot for PC1 \& PC2 contributing volatile peaks and their assignments, with each volatile denoted by its KI value.

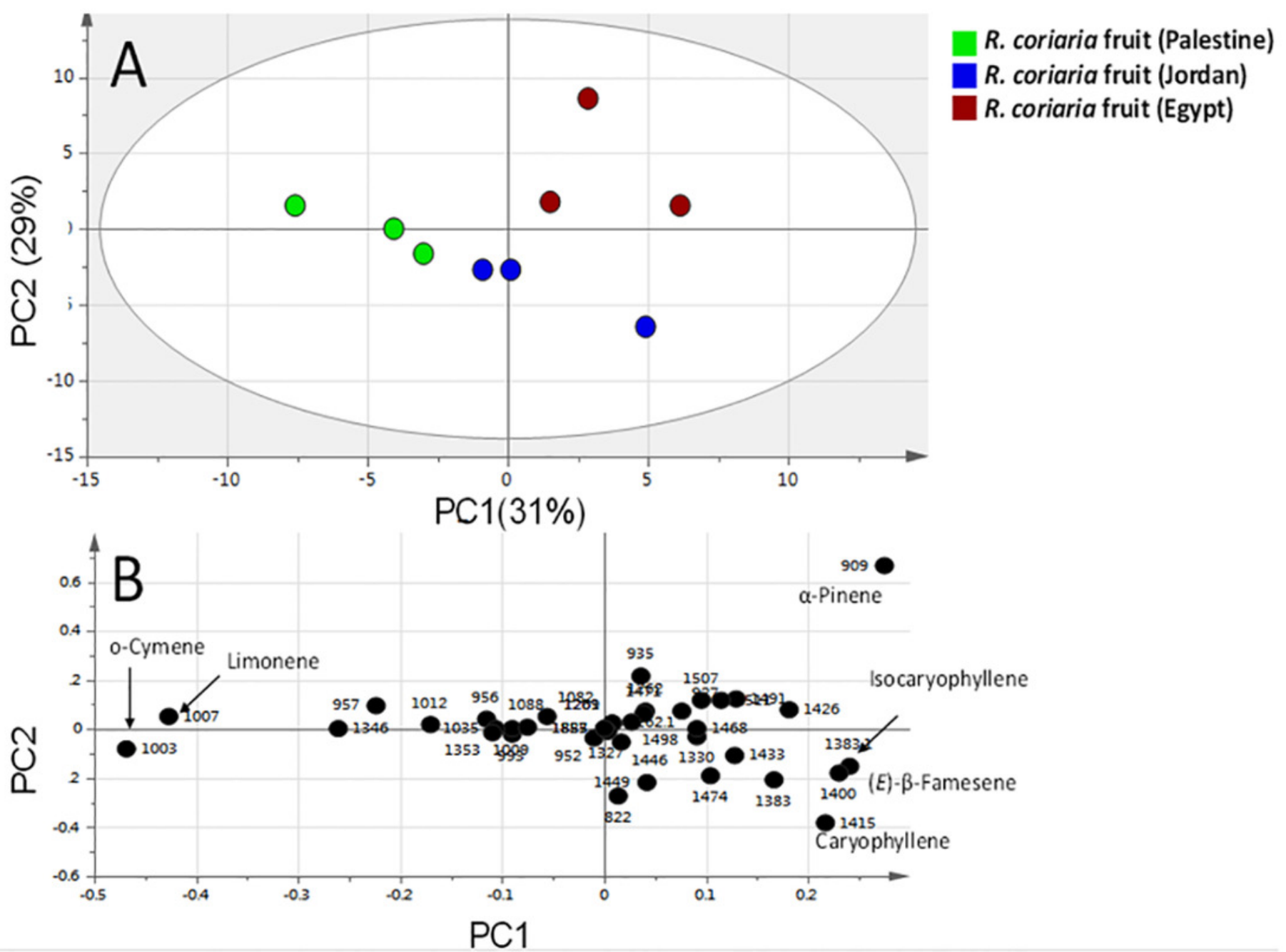




\section{Figure 4}

Principal component analyses of fresh, roasted and cold beverage Rhus coriaria fruit (Sumac) analyzed by SPME-GC-MS $(n=3)$.

Clusters are located at the distinct positions in two-dimensional space described by two vectors of principal component $1(P C 1)=45 \%$ and PC2 $=24 \%$. (A) Score Plot of PC1 vs. PC2 scores. (B) Loading plot for PC1 \& PC2 contributing mass peaks and their assignments, with each volatile denoted by its KI value.

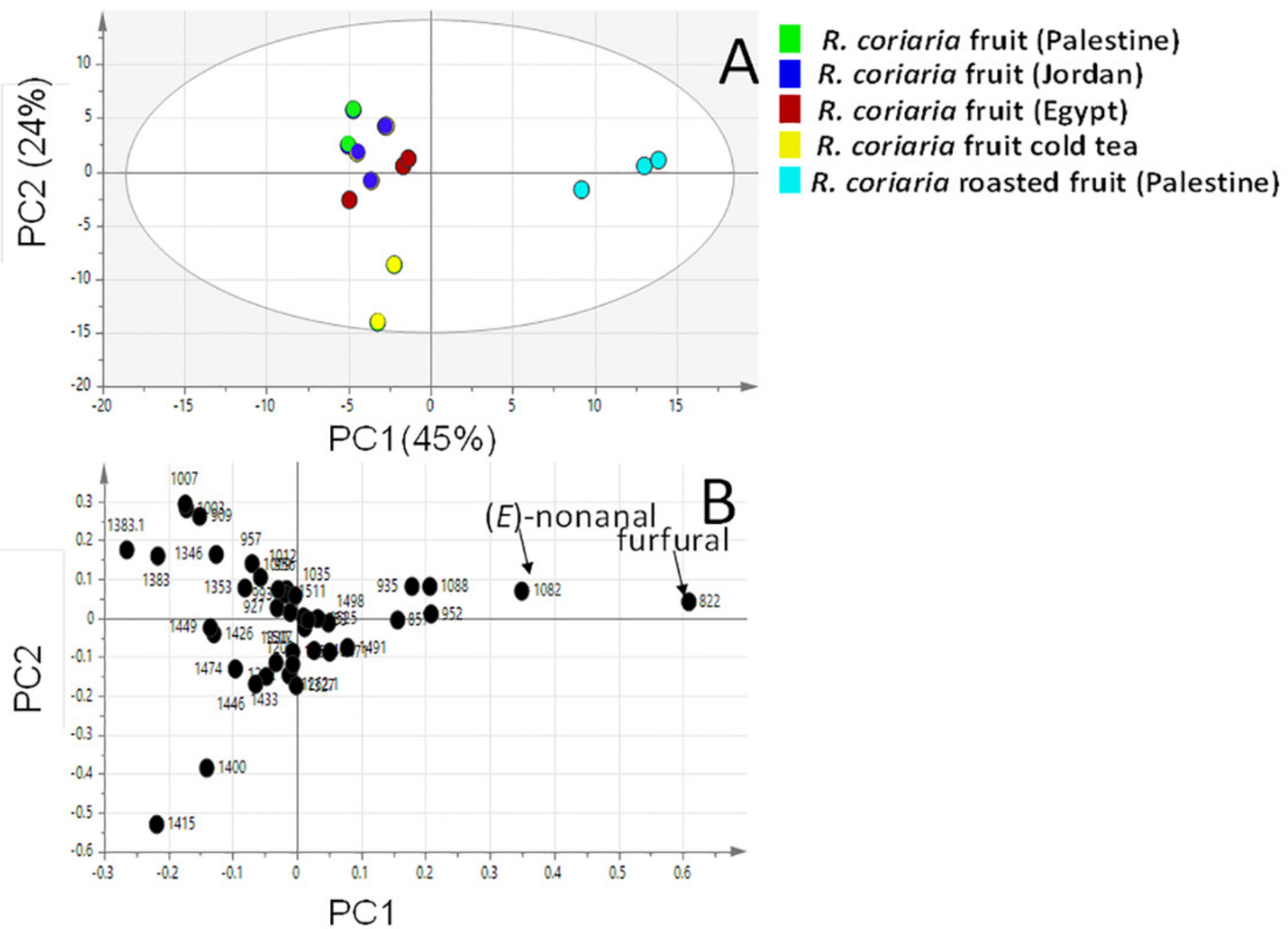




\section{Table $\mathbf{1}$ (on next page)}

Relative percentage of volatile compounds detected in fresh $R$. coriaria fruit (Sumac) from 3 Middle East sites and in response to roasting using SPME-GC-MS measurements $(n=3)$. 
1 Table 1: Relative percentage of volatile compounds detected in fresh $R$. coriaria fruit (Sumac) from 3

2 Middle East sites and in response to roasting using SPME-GC-MS measurements $(\mathrm{n}=3)$. The \%

3 identified for each class is bolded, while the main component from each site is underlined and bolded.

\begin{tabular}{|c|c|c|c|c|c|c|c|c|c|c|c|}
\hline \multirow{3}{*}{\multicolumn{2}{|c|}{$\begin{array}{c}\text { Volatile } \\
\text { constituents }\end{array}$}} & \multirow{3}{*}{ RT } & \multirow{3}{*}{$\mathbf{K I}$} & \multicolumn{6}{|c|}{ Fresh Sumac } & \multirow{2}{*}{\multicolumn{2}{|c|}{$\begin{array}{c}\text { Roasted Sumac } \\
\text { Palestine }\end{array}$}} \\
\hline & & & & \multicolumn{2}{|c|}{ Egypt } & \multicolumn{2}{|c|}{ Jordan } & \multicolumn{2}{|c|}{ Palestine } & & \\
\hline & & & & \multicolumn{8}{|c|}{ Average (S.D.) } \\
\hline \multicolumn{12}{|c|}{ Alcohols } \\
\hline 1 & $\beta$-Linalool & 9.93 & 1077 & 3.38 & $(1.17)$ & 1.84 & $(1.60)$ & 0.90 & $(0.43)$ & 0.28 & $(0.24)$ \\
\hline 2 & endo-Borneol & 11.116 & 1158 & 0.00 & $(0.00)$ & 0.06 & $(0.05)$ & 0.01 & $(0.02)$ & 0.20 & $(0.08)$ \\
\hline 3 & 4-Terpineol & 11.183 & 1163 & 0.23 & $(0.31)$ & 0.52 & $(0.49)$ & 0.00 & $(0.00)$ & 0.03 & $(0.05)$ \\
\hline 4 & $\alpha$-Terpineol & 11.408 & 1179 & 0.54 & $(0.48)$ & 0.03 & $(0.06)$ & 0.02 & $(0.03)$ & 0.00 & $(0.00)$ \\
\hline \multicolumn{4}{|c|}{ Total alcohols } & 4.15 & & 2.46 & & 0.93 & & 0.51 & \\
\hline \multicolumn{12}{|c|}{ Aromatics } \\
\hline 5 & Styrene & 6.433 & 874 & 0.20 & $(0.30)$ & 0.69 & $(0.64)$ & 1.08 & $(0.69)$ & 0.03 & $(0.05)$ \\
\hline 6 & Naphthalene & 11.328 & 1176 & 0.00 & $(0.00)$ & 15.88 & $(4.18)$ & 0.00 & $(0.00)$ & 0.00 & $(0.00)$ \\
\hline \multicolumn{4}{|c|}{ Total aromatics } & 0.20 & & $\overline{16.56}$ & & 1.08 & & 0.03 & \\
\hline \multicolumn{12}{|c|}{ Esters } \\
\hline 7 & $\begin{array}{l}\text { Methyl } \\
\text { nonanoate }\end{array}$ & 11.608 & 1193 & 1.30 & $(2.08)$ & 0.26 & $(0.25)$ & 0.00 & $(0.00)$ & 0.10 & $(0.18)$ \\
\hline 8 & Bornyl formate & 11.833 & 1209 & 0.00 & $(0.00)$ & 0.00 & $(0.00)$ & 0.01 & $(0.03)$ & 0.07 & $(0.09)$ \\
\hline 9 & linalyl acetate & 11.958 & 1219 & 0.24 & $(0.41)$ & 0.03 & $(0.06)$ & 0.02 & $(0.03)$ & 0.09 & $(0.13)$ \\
\hline 10 & Bornyl acetate & 12.523 & 1261 & 0.00 & $(0.00)$ & 0.00 & $(0.00)$ & 0.01 & $(0.03)$ & 0.07 & $(0.09)$ \\
\hline 11 & $\begin{array}{l}\text { Isobornyl } \\
\text { formate }\end{array}$ & 12.534 & 1262 & 0.00 & $(0.00)$ & 0.00 & $(0.00)$ & 0.01 & $(0.03)$ & 0.07 & $(0.09)$ \\
\hline 12 & Nerol acetate & 13.36 & 1327 & 0.00 & $(0.00)$ & 0.10 & $(0.09)$ & 0.03 & $(0.05)$ & 0.29 & $(0.21)$ \\
\hline \multicolumn{4}{|c|}{ Total esters } & 1.54 & & 0.39 & & 0.09 & & 0.68 & \\
\hline \multicolumn{12}{|c|}{ Ethers } \\
\hline 13 & Estragole & 11.393 & 1177 & 0.00 & $(0.00)$ & 0.00 & $(0.00)$ & 0.00 & $(0.00)$ & 0.00 & $(0.00)$ \\
\hline 14 & $\begin{array}{l}\text { Allyl p- } \\
\text { methylbenzyl } \\
\text { ether }\end{array}$ & 13.598 & 1346 & 4.46 & $(1.37)$ & 0.89 & $(0.29)$ & 2.27 & $(2.77)$ & 0.38 & $(0.24)$ \\
\hline 15 & Precocene I & 14.725 & 1439 & 1.70 & $(2.45)$ & 0.29 & \begin{tabular}{|l|}
$(0.25)$ \\
\end{tabular} & 0.35 & $(0.27)$ & 0.34 & $(0.56)$ \\
\hline \multicolumn{4}{|c|}{ Total ethers } & 6.17 & & 1.17 & & 2.62 & & 0.72 & \\
\hline \multicolumn{12}{|c|}{ Furan/aldehydes } \\
\hline 16 & Furfural & 5.35 & 822 & 0.32 & $(0.34)$ & 3.73 & $(3.26)$ & 0.00 & $(0.00)$ & $\underline{\mathbf{3 4 . 3 7}}$ & $(10.55)$ \\
\hline 17 & $\begin{array}{c}\text { Maleic } \\
\text { anhydride }\end{array}$ & 6.092 & 857 & 0.00 & $(0.00)$ & 0.00 & $(0.00)$ & 0.00 & $(0.00)$ & 2.57 & $(0.63)$ \\
\hline 18 & $\begin{array}{l}\text { Itaconic } \\
\text { anhydride }\end{array}$ & 7.599 & 935 & 0.90 & $(0.53)$ & 0.29 & $(0.38)$ & 1.80 & $(0.57)$ & 4.29 & $(0.48)$ \\
\hline 19 & $\begin{array}{l}\text { Furfural, 5- } \\
\text { methyl- }\end{array}$ & 7.893 & 952 & 0.00 & $(0.00)$ & 0.19 & $(0.33)$ & 0.00 & $(0.00)$ & 3.91 & $(1.13)$ \\
\hline 20 & Octanal & 8.408 & 982 & 1.22 & $(0.85)$ & 0.65 & $(0.57)$ & 0.36 & $(0.23)$ & 0.47 & $(0.36)$ \\
\hline 21 & Nonanal & 10.008 & 1082 & 1.37 & $(1.93)$ & 0.76 & $(0.84)$ & 0.93 & $(0.86)$ & 12.20 & $(5.08)$ \\
\hline 22 & Decanal & 11.418 & 1181 & 0.00 & $(0.00)$ & 0.00 & $(0.00)$ & 0.00 & $(0.00)$ & 0.00 & $(0.00)$ \\
\hline 23 & (Z)-2-Decenal & 12.204 & 1237 & 0.18 & $(0.26)$ & 0.55 & $(0.47)$ & 0.40 & $(0.19)$ & 0.38 & $(0.46)$ \\
\hline \multicolumn{4}{|c|}{ Total furan/aldehydes } & 3.99 & & 6.17 & & 3.49 & & 58.19 & \\
\hline \multicolumn{12}{|c|}{ Hydrocarbons } \\
\hline $2 p$ & IJ PeoderaingePDF | & $8 . \mathrm{d} z 2 \mathrm{2}+\mathrm{GO}$ & 1:2:1:Ne & W 6 Jun & $8(0.00)$ & 0.03 & $(0.05)$ & 0.00 & $(0.00)$ & 0.00 & $(0.00)$ \\
\hline \multicolumn{4}{|c|}{ Total hydrocarbons } & 0.00 & & 0.03 & & 0.00 & & 0.00 & \\
\hline
\end{tabular}




\begin{tabular}{|c|c|c|c|c|c|c|c|c|c|c|c|}
\hline \multicolumn{12}{|c|}{ Ketones } \\
\hline 25 & Camphenone, 6- & 9.34 & 1039 & 1.20 & $(1.16)$ & 0.29 & $(0.26)$ & 0.42 & $(0.20)$ & 0.56 & $(0.22)$ \\
\hline 26 & Acetophenone & 9.549 & 1052 & 0.18 & $(0.15)$ & 0.00 & $(0.00)$ & 0.01 & $(0.02)$ & 0.00 & $(0.00)$ \\
\hline 27 & 3-Thujanone & 10.105 & 1088 & 0.93 & $(0.59)$ & 0.89 & $(0.77)$ & 0.84 & $(0.07)$ & 5.16 & (3.74) \\
\hline 28 & Camphor & 10.758 & 1133 & 0.00 & $(0.00)$ & 0.00 & $(0.00)$ & 0.00 & $(0.00)$ & 0.00 & $(0.00)$ \\
\hline 29 & $p$-Menthone & 10.822 & 1137 & 0.00 & $(0.00)$ & 0.00 & $(0.00)$ & 0.00 & $(0.00)$ & 0.00 & $(0.00)$ \\
\hline 30 & Pyranone & 10.917 & 1144 & 0.00 & $(0.00)$ & 0.00 & $(0.00)$ & 0.00 & $(0.00)$ & 0.40 & $(0.68)$ \\
\hline 31 & Carvone & 12.075 & 1228 & 0.00 & $(0.00)$ & 0.03 & $(0.06)$ & 0.00 & $(0.00)$ & 0.02 & $(0.03)$ \\
\hline \multicolumn{4}{|c|}{ Total ketones } & 2.30 & & 1.21 & & 1.26 & & 6.14 & \\
\hline \multicolumn{12}{|c|}{ Monoterpene hydrocarbon } \\
\hline 32 & $\alpha$-Pinene & 7.143 & 909 & 4.05 & $(1.55)$ & 1.98 & $(0.15)$ & $\underline{16.70}$ & $(5.56)$ & 2.01 & $(1.81)$ \\
\hline 33 & $\alpha$-Fenchene & 7.45 & 927 & 0.18 & $(0.16)$ & 0.00 & $(0.00)$ & 0.80 & $(0.52)$ & 0.04 & $(0.04)$ \\
\hline 34 & $\beta$-Pinene & 7.948 & 957 & 1.79 & $(1.46)$ & 0.50 & $(0.44)$ & 0.84 & $(0.52)$ & 0.11 & $(0.06)$ \\
\hline 35 & $\beta$-Myrcene & 7.95 & 956 & 0.88 & $(0.54)$ & 0.18 & $(0.16)$ & 0.17 & $(0.29)$ & 0.17 & $(0.12)$ \\
\hline 36 & $\beta$-Thujene & 8.483 & 986 & 1.06 & $(0.52)$ & 0.82 & $(0.31)$ & 1.39 & $(1.84)$ & 0.59 & $(0.83)$ \\
\hline 37 & 4-Carene & 8.602 & 993 & 0.42 & $(0.29)$ & 0.31 & $(0.27)$ & 0.08 & $(0.14)$ & 0.09 & $(0.02)$ \\
\hline 38 & $\begin{array}{l}1,3,8-\mathrm{p}- \\
\text { Menthatriene }\end{array}$ & 8.745 & 1001 & 1.42 & $(0.19)$ & 0.81 & $(0.71)$ & 0.28 & $(0.33)$ & 0.02 & $(0.03)$ \\
\hline 39 & O-Cymene & 8.768 & 1003 & $\underline{7.73}$ & $(1.27)$ & 4.25 & $(1.87)$ & 2.40 & $(0.82)$ & 0.23 & $(0.09)$ \\
\hline 40 & Limonene & 8.827 & 1007 & 7.36 & (3.63) & 3.36 & $(0.73)$ & 3.90 & $(1.03)$ & 0.73 & $(0.12)$ \\
\hline 41 & $\beta$-Phellandrene & 8.849 & 1009 & 0.47 & $(0.15)$ & 0.55 & $(0.49)$ & 0.22 & $(0.38)$ & 0.08 & $(0.02)$ \\
\hline 42 & $\beta$-Ocimene & 9.042 & 1020 & 7.50 & $(0.80)$ & 3.83 & $(2.93)$ & 3.21 & $(1.63)$ & 0.85 & $(0.41)$ \\
\hline 43 & $\gamma$-Terpinene & 9.283 & 1036 & 0.66 & $(0.43)$ & 0.29 & $(0.25)$ & 0.08 & $(0.14)$ & 0.13 & $(0.09)$ \\
\hline 44 & $\beta$-Terpinene & 9.289 & 1035 & 0.33 & $(0.15)$ & 0.17 & $(0.16)$ & 0.06 & $(0.11)$ & 0.19 & $(0.04)$ \\
\hline 45 & $\begin{array}{l}\text { Unknown } \\
\text { monterpene }\end{array}$ & 9.7171 & 1063 & 0.38 & $(0.17)$ & 0.17 & $(0.23)$ & 0.03 & $(0.05)$ & 0.06 & $(0.00)$ \\
\hline 46 & $p$-Cymenene & 9.81 & 1069 & 0.10 & $(0.17)$ & 0.11 & $(0.10)$ & 0.00 & $(0.00)$ & 0.02 & $(0.03)$ \\
\hline 47 & $\begin{array}{l}\text { Unknown } \\
\text { monoterpene }\end{array}$ & 12.533 & 1262 & 0.00 & $(0.00)$ & 0.00 & $(0.00)$ & 0.15 & $(0.15)$ & 0.18 & $(0.20)$ \\
\hline \multicolumn{4}{|c|}{ Total monoterpene hydrocarbon } & 34.33 & & 17.33 & & 30.32 & & 5.51 & \\
\hline \multicolumn{12}{|c|}{ Oxides } \\
\hline 48 & Cineole & 8.908 & 1012 & 7.27 & $(2.98)$ & 3.25 & $(0.81)$ & 2.23 & $(0.15)$ & 0.53 & $(0.31)$ \\
\hline \multicolumn{4}{|c|}{ Total oxides } & 7.27 & & 3.25 & & 2.23 & & $\mathbf{0 . 5 3}$ & \\
\hline \multicolumn{12}{|c|}{ Sesquiterpene hydrocarbon } \\
\hline 49 & $\begin{array}{l}\text { Unknown } \\
\text { sesquiterpene }\end{array}$ & 12.631 & 1270 & 0.00 & $(0.00)$ & 0.13 & $(0.11)$ & 0.01 & $(0.02)$ & 0.06 & $(0.08)$ \\
\hline 50 & $\alpha$-Longipinene & 13.393 & 1330 & 0.00 & $(0.00)$ & 0.78 & $(0.25)$ & 0.53 & $(0.46)$ & 0.17 & $(0.21)$ \\
\hline 51 & Copaene & 13.662 & 1352 & 0.00 & $(0.00)$ & 0.17 & $(0.15)$ & 0.17 & $(0.22)$ & 0.12 & $(0.10)$ \\
\hline 52 & $\alpha$-Cubebene & 13.675 & 1353 & 1.29 & $(0.40)$ & 0.60 & $(0.07)$ & 0.93 & $(0.67)$ & 0.27 & $(0.22)$ \\
\hline 53 & Isocaryophyllene & 14.042 & 1383 & 4.42 & $(0.52)$ & 5.26 & $(0.81)$ & 5.76 & $(0.81)$ & 0.50 & $(0.74)$ \\
\hline 54 & $(E)$ - $\beta$-Famesene & 14.05 & 1383 & 6.05 & $(1.69)$ & 6.58 & $(1.94)$ & 8.26 & $(1.49)$ & 0.07 & $(0.03)$ \\
\hline
\end{tabular}




\begin{tabular}{|c|c|c|c|c|c|c|c|c|c|c|c|}
\hline 55 & $\begin{array}{c}(Z, Z)-\alpha- \\
\text { Farnesene }\end{array}$ & 14.119 & 1389 & 6.02 & $(1.98)$ & 7.62 & $(1.97)$ & 8.60 & $(1.41)$ & 6.84 & (6.42) \\
\hline 56 & Longifolene & 14.2 & 1396 & 4.42 & $(0.52)$ & 5.23 & $(0.81)$ & 5.73 & $(0.84)$ & 4.81 & (3.96) \\
\hline 57 & Caryophyllene & 14.252 & 1400 & 4.46 & $(1.37)$ & 5.29 & $(1.33)$ & 6.21 & $(1.13)$ & 4.21 & (3.11) \\
\hline 58 & $\begin{array}{l}(E) \text { - } \beta \text {-Famesene } \\
\text { isomer }\end{array}$ & 14.433 & 1415 & 3.72 & $(2.69)$ & 6.51 & $(2.00)$ & 5.73 & $(5.12)$ & 0.64 & $(0.67)$ \\
\hline 59 & Aromadendrene & 14.558 & 1425 & 2.15 & $(3.04)$ & 3.70 & $(5.72)$ & 2.74 & $(4.10)$ & 0.45 & $(0.30)$ \\
\hline 60 & Farnesene isomer & 14.575 & 1426 & 1.29 & $(0.40)$ & 1.75 & $(0.15)$ & 2.81 & $(0.97)$ & 0.38 & $(0.42)$ \\
\hline 61 & $\alpha$-Humulene & 14.662 & 1433 & 0.93 & $(0.50)$ & 1.48 & $(0.40)$ & 1.49 & $(0.22)$ & 1.29 & $(0.90)$ \\
\hline 62 & $\begin{array}{l}\text { (Z)-Muurola- } \\
4(14), 5 \text {-diene }\end{array}$ & 14.817 & 1446 & 1.29 & $(0.40)$ & 0.75 & $(0.79)$ & 1.25 & $(0.40)$ & 0.96 & $(0.67)$ \\
\hline 63 & Germacrene D & 14.841 & 1449 & 2.83 & $(2.38)$ & 2.46 & $(3.56)$ & 2.34 & $(2.71)$ & 0.82 & $(0.61)$ \\
\hline 64 & $\gamma$-Muurolene & 15.083 & 1468 & 0.00 & $(0.00)$ & 0.27 & $(0.24)$ & 0.51 & $(0.79)$ & 0.60 & $(0.17)$ \\
\hline 65 & $\alpha$-Muurolene & 15.123 & 1471 & 0.26 & $(0.23)$ & 0.17 & $(0.22)$ & 0.37 & $(0.32)$ & 0.90 & $(0.58)$ \\
\hline 66 & $\beta$-Bisabolene & 15.153 & 1474 & 0.93 & $(0.50)$ & 1.64 & $(0.27)$ & 1.29 & $(1.16)$ & 0.39 & $(0.32)$ \\
\hline 67 & $\gamma$-Cadinene & 15.342 & 1489 & 0.00 & $(0.00)$ & 0.00 & $(0.00)$ & 0.35 & $(0.32)$ & 0.82 & $(0.55)$ \\
\hline 68 & $\delta$-Cadinene, $(+)-$ & 15.359 & 1491 & 0.00 & $(0.00)$ & 0.28 & $(0.27)$ & 1.04 & $(0.91)$ & 1.79 & (1.18) \\
\hline 69 & Calamenene & 15.442 & 1498 & 0.00 & $(0.00)$ & 0.17 & $(0.15)$ & 0.17 & $(0.20)$ & 0.50 & $(0.29)$ \\
\hline 70 & $\begin{array}{l}\text { Naphthalene, } \\
1,2,3,4,4 \mathrm{a}, 7- \\
\text { hexahydro-1,6- } \\
\text { dimethyl-4-(1- } \\
\text { methylethyl)- } \\
\end{array}$ & 15.575 & 1507 & 0.00 & $(0.00)$ & 0.17 & $(0.15)$ & 0.68 & $(0.61)$ & 0.36 & $(0.24)$ \\
\hline 71 & $\begin{array}{l}\text { Unknown } \\
\text { sesquiterpene }\end{array}$ & 15.628 & 1511 & 0.00 & $(0.00)$ & 0.41 & $(0.40)$ & 0.98 & $(0.86)$ & 0.30 & $(0.19)$ \\
\hline 72 & $\alpha$-Calacorene & 15.705 & 1517 & 0.00 & $(0.00)$ & 0.03 & $(0.05)$ & 0.03 & $(0.04)$ & 0.30 & $(0.11)$ \\
\hline 73 & $\begin{array}{l}\text { Unknown } \\
\text { sesquiterpene }\end{array}$ & 15.977 & 1525 & 0.00 & $(0.00)$ & 0.00 & $(0.00)$ & 0.00 & $(0.00)$ & 0.11 & $(0.03)$ \\
\hline 74 & $\begin{array}{l}\text { Unknown } \\
\text { sesquiterpene }\end{array}$ & 21.707 & 1853 & 0.00 & $(0.00)$ & 0.00 & $(0.00)$ & 0.00 & $(0.00)$ & 0.03 & $(0.06)$ \\
\hline \multicolumn{4}{|c|}{ Total sesquiterpene hydrocarbon } & 40.06 & & 51.44 & & 57.98 & & 27.71 & \\
\hline \multicolumn{4}{|c|}{ Total volatiles } & 100.00 & 0.00 & 100.00 & 0.00 & 100.00 & $\mathbf{0 . 0 0}$ & 100.00 & $\mathbf{0 . 0 0}$ \\
\hline
\end{tabular}

4 Relative percentage of volatile compounds detected in fresh $R$. coriaria fruit (Sumac) from 3 Middle East

5 sites and in response to roasting using SPME-GC-MS measurements $(n=3)$. The \% identified for each

6 class is bolded, while the main component from each site is underlined and bolded. 


\section{Table 2 (on next page)}

Relative percentile (\%) of the 10 classes of volatile compounds detected in fresh and roasted $R$. coriaria fruit (Sumac) from 3 Middle East sites as analyzed using SPMEGC-MS 
1 Table 2: Relative percentile (\%) of the 10 classes of volatile compounds detected in fresh and roasted $R$. 2 coriaria fruit (Sumac) from 3 Middle East sites as analyzed using SPME-GC-MS.

\begin{tabular}{|c|c|c|c|c|c|}
\hline \multirow{3}{*}{$\begin{array}{l}\text { No. of volatile } \\
\text { constituents }\end{array}$} & \multirow{3}{*}{ Class } & \multicolumn{3}{|c|}{ Fresh Sumac } & \multirow{2}{*}{$\begin{array}{c}\text { Roasted Sumac } \\
\text { Palestine }\end{array}$} \\
\hline & & Egypt & Jordan & Palestine & \\
\hline & & \multicolumn{4}{|c|}{ Average (\%) } \\
\hline 4 & Total alcohols & 4.15 & 2.46 & 0.93 & 0.51 \\
\hline 2 & Total aromatics & 0.20 & 16.56 & 1.08 & 0.03 \\
\hline 6 & Total esters & 1.54 & 0.39 & 0.09 & 0.68 \\
\hline 3 & Total ethers & 6.17 & 1.17 & 2.62 & 0.72 \\
\hline 8 & Total furan/aldehyde & 3.99 & 6.17 & 3.49 & 58.2 \\
\hline 1 & Total hydrocarbons & 0 & 0.03 & 0 & 0 \\
\hline 7 & Total ketones & 2.30 & 1.21 & 1.26 & 6.14 \\
\hline 16 & $\begin{array}{l}\text { Total monoterpene } \\
\text { Hydrocarbons }\end{array}$ & 34.33 & 17.33 & 30.3 & 5.51 \\
\hline 1 & Total oxide & 7.27 & 3.25 & 2.23 & 0.53 \\
\hline 26 & $\begin{array}{c}\text { Total sesquiterpene } \\
\text { hydrocarbon }\end{array}$ & 40.06 & 51.44 & 58 & 27.7 \\
\hline
\end{tabular}

3

4 